\title{
Relationship of Dental Caries with Fluoride Concentration in Unstimulated whole Saliva of 7 to 15-year-old Nonfluoride Users
}

\author{
${ }^{1}$ Manjit Talwar, ${ }^{2}$ Amrit Tewari, ${ }^{3}$ Harpinder Singh Chawla, ${ }^{4}$ Vinod Sachdev, ${ }^{5}$ Suresh Sharma
}

\section{ABSTRACT}

Objective: The objective of the present study was to investigate the relationship between dental caries and fluoride concentration in unstimulated whole saliva of non-fluoride users.

Study design: Ninety subjects, aged 7 to 15 years who were non-fluoride users, participated in the study. Dental caries was recorded using modified Moller's index. Unstimulated whole saliva samples were collected early in the morning. Fluoride concentration in saliva was estimated using combination ion specific fluoride electrode (Orion). Water fluoride of the area ranged from 0.34 to $0.38 \mathrm{ppm}$.

Results: Salivary fluoride concentration (mean \pm SE) in saliva ( $\mathrm{n}=90$ ) was $0.03 \pm 0.03 \mathrm{ppm}$ with a range of 0.01 to 0.24 ppm. The DMFT \pm SE was $3.26 \pm 0.27$ and DMFS $4.30 \pm 0.42$. Correlation of fluoride concentration in saliva was inverse and significant with DMFT $(p<0.01)$ and DMFS $(p<0.01)$ using the Spearman's rank correlation coefficient.

Conclusion: Fluoride concentration in saliva could be an indication of the individual's caries risk and help isolating high risk individuals requiring special chairside preventive strategies.

Keywords: Fluoride, Dental caries, Unstimulated saliva.

How to cite this article: Talwar M, Tewari A, Chawla HS, Sachdev V, Sharma S. Relationship of Dental Caries with Fluoride Concentration in Unstimulated whole Saliva of 7 to 15-yearold Nonfluoride Users. Int J Experiment Dent Sci 2014;3(2): 59-62.

Source of support: Nil

Conflict of interest: None

\footnotetext{
${ }^{1}$ Associate Professor, ${ }^{2-5}$ Professor

${ }^{1}$ Department of Oral Health Center, Government Medical College and Hospital, Chandigarh, India

${ }^{2,3}$ Department of Oral Health Sciences Center, Postgraduate Institute of Medical Education and Research, Chandigarh, India

${ }^{4}$ Department of Pedodontics, Himachal Dental College, Sundar Nager, Himachal Pradesh, India

${ }^{5}$ Department of Statistics, Panjab University, Chandigarh, India

Corresponding Author: Manjit Talwar, Associate Professor Department of Oral Health Center, Government Medical College and Hospital, Chandigarh, India, Phone: 911722665253, e-mail: talwarmanjit@gmail.com
}

\section{INTRODUCTION}

The fluoride in the oral environment has an important role in demineralization and remineralization. ${ }^{1}$ It has been shown in vitro that fluoride concentration below $2 \mathrm{ppm}(105.3$ $\mu \mathrm{mol} / \mathrm{l})$ in the solution can influence demineralization and remineralization of enamel and the effect is related to the fluoride concentration in saliva or other ambient fluids that surround the surfaces of the teeth. ${ }^{1}$ Availability of fluoride in the oral environment is determined by the supply of fluoride by its periodic use in one form or the other and the factors affecting retention (binding of fluoride ions to plaque, enamel, soft tissues) and factors influencing its clearance (salivary flow rate, oral muscular movements, eating, drinking, etc.). Fluoride in unstimulated whole saliva is a cumulative reflection of the sum of fluoride present in various hard and soft tissue retention sites in the oral cavity. ${ }^{2}$ Concentration of fluoride in saliva available for clinically significant influence on cariostasis is low but its availability may be important for prevention of demineralization and enhancement of remineralization. Most studies in this direction, have been carried out in populations which have been regularly using fluoride in one form or the other, which has a masking effect. It has been proposed that the cariostatic effect of fluoride is attributed to its continuous presence in low ionic concentrations in the oral environment. ${ }^{3-6}$ Few studies have correlated the human caries susceptibility with salivary fluoride concentration. ${ }^{7-10}$

The present investigation was carried out to assess the availability of fluoride in saliva of nonfluoride users and its relationship to dental caries experience.

\section{MATERIALS AND METHODS}

\section{Sample Selection}

The investigation was carried out in 90 school children in the age group of 7 to 15 years who were residing in boarding schools in the urban north-west zone of Chandigarh, India. Permission in written, to conduct the study was taken from the principal of the schools along with written informed consent from the parents/guardians of the children. The subjects selected were non-tea drinkers, had similar socioeconomic status and dietary habits and had no history of 
exposure to topical or systemic fluoride. The water fluoride concentration of the area ranged from 0.34 to $0.38 \mathrm{ppm}$.

\section{Dental Caries Recording}

Dental caries was recorded using modified Moller's index ${ }^{11}$ with the aid of a plain mouth mirror and a standardized stainless steel explorer with diameter of the tip of the explorer in the range of 40 to $60 \mu$. Special care was taken to avoid applying too much pressure on the teeth of the subjects while examining. The children were examined in broad daylight with their face directed toward sunlight. The oral examination was carried out using a simple chair in a field setting. The teeth were dried with cotton rolls and then recording was done. Radiographs were not taken. Before recording, the investigator was calibrated by the chief supervisor (AT). A constant check was kept on intra-examiner variability.

\section{Collection, Transportation and Storage of Saliva Samples}

Unstimulated whole saliva $(1 \mathrm{ml})$ sample was collected from each of the 90 children by asking the subjects to bend the head forward, which facilitated pooling of saliva in the oral cavity. Saliva sample was drooled into the plastic vials. Whole unstimulated saliva was considered appropriate as it is representative of saliva which influences biological events in the mouth for most of the day. ${ }^{2}$ Collection of saliva sample was done early in the morning (6-6.30 am) on rising without the subjects eating or drinking anything or brushing their teeth. Acid washed screw capped plastic vials were used for collection of saliva samples. In between snacking was permitted.

\section{Transportation and Storage of Saliva Samples}

After saliva collection, the plastic vials were placed upright in a storage box and transported within 30 minutes to the Oral Health Sciences Centre, Postgraduate Institute of Medical Education and Research, Chandigarh, and stored at $4^{\circ} \mathrm{C}$ until analysis. ${ }^{2}$

\section{Estimation of Fluoride in the Saliva Samples}

The stored saliva samples were analyzed within a week of collection. They were brought to room temperature (room temperature was kept at $25^{\circ} \mathrm{C}$ ) and treated with TISAB III buffer (Orion Inc, USA Cat no. 940911). One milliliter saliva was pipetted into another plastic vial and $0.1 \mathrm{ml}$ buffer was added as per the manufacturer's instructions. Fluoride in saliva was estimated with a combination ion specific fluoride electrode (Orion model 96-09) coupled to an ion analyzer. Solutions of $0.001,0.01,0.1,1.0$ and 10 ppm F (serially diluted from a 100 ppm F standard Orion no. 940907) and 100 ppm fluoride were used to obtain a fluoride calibration curve.

\section{Statistical Analysis}

Normality of the variables was tested, using normal quantile (Q-Q) plots and it was observed that there was a deviation from normality. In order to find out the relation between decayed, missing and filled teeth (DMFT) and decayed, missing and filled surfaces (DMFS) with fluoride concentration in saliva of all 90 subjects, Spearman's rank correlation was computed. The data were classified into three groups and for comparison of these groups Kruskal-Wallis one-way analysis of variance (ANOVA) followed by post-hoc tests was carried out separately for DMFT and DMFS.

\section{RESULTS}

Correlation coefficients of dental caries status of 7 to 15 -year-old children with fluoride concentration in saliva were found to be inverse and significant for DMFT $(\mathrm{p}<0.01)$ and DMFS $(\mathrm{p}<0.01)$ indicating that as fluoride concentration in saliva decreased the dental caries increased (DMFT and DMFS). No statistically significant difference was observed in the deciduous dentition decayed, extracted filled teeth and decayed, extracted filled surface (DEFT and DEFS, Table 1). The 90 subjects examined were divided into three (low, moderate, high) groups based on fluoride concentration in saliva as shown in Table 2. Low salivary fluoride concentration group had the highest mean \pm SE score for DMFT and DMFS, i.e. $4.09 \pm 0.38$ and $5.54 \pm$ 0.57 , followed by moderate salivary concentration group with DMFT of $2.46 \pm 0.44$ and DMFS of $3.10 \pm 0.68$ and the high salivary fluoride concentration group had the lowest score, with DMFT of $1.45 \pm 0.31$ and DMFS of 1.54 \pm 0.31 (Table 3). This difference was not observed for the deciduous dentition.

Table 1: Spearman's rank correlation of dental caries status of 7 to 15 -year-old children with fluoride concentration in saliva $(n=90)$

\begin{tabular}{llll}
\hline $\begin{array}{l}\text { Baseline salivary fluoride } \\
\text { concentration }(\mathrm{ppm})(\text { mean } \pm \text { SE) }\end{array}$ & $\begin{array}{l}\text { Caries status } \\
(\text { mean } \pm \text { SE) }\end{array}$ & $\begin{array}{l}\text { Correlation } \\
\text { coefficient }\end{array}$ & Significance \\
\hline $0.03 \pm 0.03$ & DMFT 3.26 \pm 0.27 & -0.381 & $\mathrm{p}<0.01$ \\
& DMFS $4.30 \pm 0.42$ & -0.393 & $\mathrm{p}<0.01$ \\
& DEFT $1.31 \pm 0.21$ & 0.149 & $\mathrm{NS}$ \\
& DEFS 2.25 \pm 0.46 & 0.141 & $\mathrm{NS}$ \\
\hline
\end{tabular}


Three salivary fluoride concentration groups were compared simultaneously using Kruskal-Wallis one-way ANOVA separately for DMFT, DMFS, DEFT, DEFS (Tables 4A to C). A significant difference was observed between the groups for the permanent teeth. The difference between groups I, II and groups I, III was statistically significant. However, there was statistically no significant difference between groups II and III. In DEFT and DEFS, there was no significant difference.

Table 2: Salivary fluoride concentration groups

\begin{tabular}{|c|c|c|c|}
\hline \multicolumn{2}{|c|}{ Groups } & \multirow{2}{*}{$\begin{array}{l}\text { F concentration } \\
\text { in saliva }(p p m) \\
0.01-0.02\end{array}$} & \multirow{2}{*}{$\begin{array}{l}\text { No. of subject } \\
(n=90)\end{array}$} \\
\hline I & $\begin{array}{l}\text { Low salivary fluoride } \\
\text { concentration group }\end{array}$ & & \\
\hline II & $\begin{array}{l}\text { Moderate } \\
\text { salivary fluoride } \\
\text { concentration group }\end{array}$ & $0.03-0.05$ & 28 \\
\hline III & $\begin{array}{l}\text { High salivary fluoride } \\
\text { concentration group }\end{array}$ & $>0.06$ & 11 \\
\hline
\end{tabular}

\section{DISCUSSION}

In the present investigation, there was found to be a wide variation in the fluoride concentration of saliva ranging from 0.01 to $0.24 \mathrm{ppm}$ (mean $\pm \mathrm{SE}$ of $0.03 \pm 0.03 \mathrm{ppm}$ ) for 90 children who were nonfluoride users residing in an urban area with suboptimal fluoride in the drinking water (0.34$0.38 \mathrm{ppm}$ ). Duggal et $\mathrm{al}^{9}$ analyzed saliva for $\mathrm{Zn}, \mathrm{Cu}, \mathrm{Fe}$, $\mathrm{Mn}$ and $\mathrm{F}$ by atomic absorption spectrophotometry and for fluoride with fluoride sensitive electrode. They observed that $\mathrm{Cu}$ and $\mathrm{F}$ had a consistently inverse relationship with caries experience. In their study, the mean fluoride concentration from five rural areas of Northern India ranged from 0.010.02 for subjects in contrast to the findings of the present investigation. As snacking, frequency of water consumption was not controlled, it is probable that the kinetics of fluoride in the oral environment was influenced and availability of fluoride concentration in saliva was variable.

Table 3: Caries data grouped according to low, moderate and high salivary fluoride concentration $(\mathrm{N}=90)$ along with 95\% lower limit (LL) and upper limit (UL)

\begin{tabular}{|c|c|c|c|c|c|c|c|c|c|c|c|c|c|}
\hline \multirow{3}{*}{$\begin{array}{l}\text { Saliva fluoride } \\
\text { concentration }\end{array}$} & \multirow[t]{3}{*}{$N$} & \multicolumn{3}{|c|}{ DMFT } & \multicolumn{3}{|c|}{ DMFS } & \multicolumn{3}{|c|}{$D E F T$} & \multicolumn{3}{|c|}{ DEFS } \\
\hline & & \multirow[t]{2}{*}{ Mean $\pm S E$} & \multicolumn{2}{|c|}{$95 \% \mathrm{Cl}$} & \multirow[t]{2}{*}{ Mean $\pm S E$} & \multicolumn{2}{|c|}{$95 \% \mathrm{Cl}$} & \multirow[t]{2}{*}{ Mean $\pm S E$} & \multicolumn{2}{|c|}{$95 \% \mathrm{Cl}$} & \multirow[t]{2}{*}{ Mean \pm SE } & \multicolumn{2}{|c|}{$95 \% \mathrm{Cl}$} \\
\hline & & & $L L$ & $U L$ & & $L L$ & $U L$ & & $L L$ & $U L$ & & $L L$ & $U L$ \\
\hline 0.01-0.02 & 51 & $4.09 \pm 0.38$ & 3.33 & 4.86 & $5.54 \pm 0.57$ & 4.38 & 6.71 & $1.0 \pm 0.23$ & 0.52 & 1.47 & $1.70 \pm 0.44$ & 0.81 & 2.59 \\
\hline $0.03-0.05$ & 28 & $2.46 \pm 0.44$ & 1.54 & 3.38 & $3.10 \pm 0.68$ & 1.70 & 4.50 & $1.32 \pm 0.37$ & 0.54 & 2.09 & $2.72 \pm 0.98$ & 0.26 & 4.59 \\
\hline$>0.06$ & 11 & $1.45 \pm 0.31$ & 0.75 & 2.15 & $1.54 \pm 0.31$ & 0.84 & 2.24 & $2.72 \pm 0.98$ & 0.53 & 4.91 & $4.36 \pm 1.63$ & 0.71 & 8 \\
\hline
\end{tabular}

Table 4A: Analysis of variance Kruskal-Wallis test for caries status (DMFT, DMFS, DEFT, DEFS)

\begin{tabular}{|c|c|c|c|c|c|c|}
\hline \multicolumn{7}{|c|}{ ANOVA table } \\
\hline Groups & $I(n=51)$ & $I I(n=28)$ & III $(n=11)$ & & & \\
\hline Parameters & Mean rank & Mean rank & Mean rank & Chi-square & $d f$ & Significance \\
\hline DMFT & 54.15 & 37.13 & 26.73 & 14.394 & 2 & $p<0.001$ \\
\hline DEFT & 42.59 & 46.71 & 55.91 & 3.179 & 2 & NS \\
\hline DMFS & 54.53 & 36.41 & 26.77 & 15.332 & 2 & $p<0.0001$ \\
\hline DEFS & 42.68 & 46.66 & 55.64 & 2.997 & 2 & NS \\
\hline
\end{tabular}

NS: Nonsignificance

Table 4B: Significant difference (post-hoc test) for DMFT

\begin{tabular}{llllll}
\hline & & & ANOVA Table & \\
\hline Groups & Mean difference & SEM & Significance & \multicolumn{2}{c}{ 95\% Cl for mean difference } \\
\cline { 4 - 5 } & & & & LL & UL \\
\hline I vs II & $1.6338^{*}$ & 0.58283 & NS & 0.4753 & 2.7922 \\
II vs III & 1.0097 & 0.88179 & $\mathrm{p}<0.002$ & -0.7429 & 2.7623 \\
I vs III & $-2.6435^{*}$ & 0.82377 & -4.2808 & -1.0062 \\
\hline
\end{tabular}

NS: Nonsignificance; *Significance at $<0.05$ level

Table 4C: Least significant difference (post-hoc test) for DMFS

\begin{tabular}{llllll}
\hline & & & ANOVA Table & \\
\hline Groups & Mean difference & SEM & Significance & \multicolumn{2}{c}{$95 \%$ Cl for mean difference } \\
\cline { 4 - 5 } & & & & LL & UL \\
\hline I vs II & $2.4419^{*}$ & 0.87935 & NS & 0.007 & 4.1897 \\
II vs III & 1.5617 & 1.33036 & $p<0.002$ & -1.0826 & 4.2059 \\
I vs III & $-4.0036^{*}$ & 1.24288 & -6.4739 & -1.5332 \\
\hline
\end{tabular}

NS: Nonsignificance; *Significance at $<0.05$ level 
In a study by Dutta et al, ${ }^{12}$ the baseline salivary fluoride concentration (collected sometime over the day) in the urban population of Chandigarh in unstimulated whole saliva of 30 non-fluoride users ranged from 0.02 to $0.07 \mathrm{ppm}$.

Dental caries status, viz DMFT and DMFS was inversely correlated to the fluoride concentration in saliva and found to be highly significant $(\mathrm{p}<0.01$, Table 1$)$. Similar findings have been reported by Leverett et al, ${ }^{8}$ Duggal et al, ${ }^{9}$ Toumba and Curzon, ${ }^{10}$ and Amanlou et al. ${ }^{13}$ However, in a study by Brunn and Thylstrup ${ }^{7}$ relating dental caries experience and fluoride in whole saliva the results were inconclusive. Farsi ${ }^{14}$ (2008) observed that salivary fluoride did not significantly correlate to dental caries. In the present study, the results indicated that as the availability of fluoride in saliva decreases, the dental caries increases, suggesting an increasing caries risk (Table 3 ).

Although most of the subjects were living under the same environmental conditions with same food habits, there are great differences in dental caries experience from one individual to another. The present observations have highlighted the possible role of the oral reservoirs, sites influencing the pharmacokinetic clearance of fluoride, the severity and nature of the cariogenic challenge ${ }^{15}$ and the composition of ambient fluids (plaque fluid, crevicular fluid, saliva) and oral hygiene habits.

The subjects in the present study had not been exposed to any topical or systemic fluoride treatments. There are many plausible explanations for the availability of fluoride in the saliva of these nonfluoride users. Extraneous sources like water and diet (turmeric, cloves and other condiments) are the most probable. Nanda ${ }^{16}$ investigated the fluoride content of foods and food ingredients commonly eaten in Northern India. He found, in particular, that many spices were relatively rich in fluoride. One child with surprisingly very high saliva fluoride concentration of $0.24 \mathrm{ppm}$ was an outlier but was considered for analysis.

\section{CONCLUSION}

Fluoride concentration in saliva is a significant predictor of dental caries in the permanent dentition (DMFT, DMFS) in the population studied. Fluoride concentration in saliva could be an indicator of the individual's caries risk in our study. It may help to isolate high risk individuals requiring special chair side preventive strategies. However, dental caries is a multifactorial disease that starts with microbiological shifts within the complex biofilm (dental plaque) ${ }^{17}$ and this may be one of the important variables for dental caries risk assessment.

\section{REFERENCES}

1. Ten Cate JM, Duijsters PPE. Influence of fluoride in solution on tooth demineralisation. II Microradiographic data. Caries Res 1983;17(6):513-519.

2. Zero DT, Fu J, Espeland MA, Featherstone JDB. Comparison of fluoride concentrations in unstimulated whole saliva following the use of fluoride dentifrices and a fluoride rinse. J Dent Res 1988;67(10):1257-1262.

3. Fejerskov O, Thylstrup A, Larsen MJ. Rational use of fluoride in caries prevention: a concept based on possible cariostatic mechanisms. Acta Odontol Scand 1981;39(4):241-249.

4. Bruun C, Lambrou D, Larsen MJ, Fejerskov O, Thylstrup A. Fluoride in mixed human saliva after different topical fluoride treatments and possible relation to caries inhibition. Community Dent Oral Epidemiol 1982;10(3):124-129.

5. Arends J, Gelhard TBFM. In vivo remineralisation of human enamel. In: Leach SA, Edgar WM, editors. Demineralisation and remineralisation of the teeth. Oxford Press Ltd; 1983. p. $1-16$.

6. Arends J, Schuthof J, Petersson L, Lodding A. Time dependence of $\mathrm{F}$ uptake in demineralised enamel from $1000 \mathrm{ppm}$ fluoride $\mathrm{NaF}$ and $\mathrm{Na}_{2} \mathrm{FPO}_{3}$ solutions. Caries Res 1985;19(5):450-453.

7. Bruun $\mathrm{C}$, Thylstrup A. Fluoride in whole saliva and dental caries experience in areas with high or low concentration of fluoride in the drinking water. Caries Res 1984;18(5):450-456.

8. Leverett DH, Adair SM, Shields CP, et al. Relationship between salivary and plaque fluoride levels and dental caries experience in fluoridated and non-fluoridated communities. Caries Res 1987; 21 Abs 57:179.

9. Duggal MS, Chawla HS, Curzon MEJ. A study of the relationship between trace element in saliva and dental caries in children. Arch Oral Biol 1991;36(12):881-884.

10. Toumba KJ, Curzon MEJ. Fluoride concentrations in saliva related to dental caries prevalence in primary teeth. Eur J Pediatric Dent 2001;2(1):15-19.

11. Moller IJ. Clinical criteria for the diagnosis of the incipient carious lesions in: Advances in Fluorine Research and Dental Caries Prevention, volume 4. Proceedings of the 12th Congress of the European Organization for research on Fluorine and Dental Caries prevention. Utrecht, The Netherlands. Pergamon Press; 1966.

12. Dutta BN, Tewari A, Chawla HS, Gauba K. Clinical evaluation of class-II restoration with silver amalgam and light cured glass ionomer cement in primary molars 1998. Thesis unpublished.

13. Amanlou M, Jafari S, Afzalianmand N, et al. Association of saliva fluoride level and socio-economic factors with dental caries in 3 to 6-year-old children in Tehran, Iran. Iranian J Pharmaceutical Res 2011;10(1):159-166.

14. Farsi N. Dental caries in relation to salivary factors in Saudi Population Groups. J Contemp Dent Pract 2008 March;9(3): 16-23.

15. Vivien-Castioni N, Baehni PC, Gurny R. Current status in oral fluoride pharmacokinetics and implications for the prophylaxis against dental caries. Eur J Pharm Biopharm 1998;45(2):101-111.

16. Nanda RS. Fluoride content of North Indian foods. Ind J Med Res 1972;60(10):1470-1482.

17. Saini R. Optical detection of dental caries. Chron Young Sci 2011;2:61. 